\title{
Preparation and characterization of irradiated carboxymethyl sago starch-acid hydrogel and its application as metal scavenger in aqueous solution
}

\begin{abstract}
Carboxymethyl sago starch-acid hydrogel was prepared via irradiation technique to remove divalent metal ions $(\mathrm{Pb}, \mathrm{Cu}$ and $\mathrm{Cd})$ from their aqueous solution. The hydrogel was characterized by using Fourier Transform Infrared (FT-IR), scanning electron microscopy (SEM) and thermogravimetric analysis (TGA). The removal of these metal ions was analyzed by using inductively coupled plasma-optic emission spectra (ICP-OES) to study the amount of metal uptake by the hydrogel. Parameters of study include effect of $\mathrm{pH}$, amount of sample, contact time, initial concentration of metal solution and reaction temperature. FTIR spectroscopy shows the CMSS hydrogel absorption peaks at $1741 \mathrm{cmi} 1,1605 \mathrm{cmī} 1$ and $1430 \mathrm{cmi} 1$ which indicates the substitution of carboxymethyl group of modified sago starch. The degradation temperature of CMSS hydrogel is higher compared to CMSS due to the crosslinking by electron beam radiation and formed a porous hydrogel. From the data obtained, about $93.5 \%, 88.4 \%$ and $85.5 \%$ of $\mathrm{Pb}, \mathrm{Cu}$ and $\mathrm{Cd}$ ions has been respectively removed from their solution under optimum condition.
\end{abstract}

Keyword: Carboxymethyl starch; Sago; Electron beam radiation; Metal scavenger; Isotherm study 